\title{
The Epidemiology and Treatment of Vitiligo: A Chinese Perspective
}

\author{
Xiaolan Ding, Juan Du and Jianzhong Zhang*
}

Department of Dermatology, Peking University People's Hospital, Beijing, P.R China

\begin{abstract}
Vitiligo is an acquired pigment disorder. It occurs worldwide, with a prevalence of $0.5 \%$ to $2 \%$. Vitiligo had profound impact on patients' quality of life. In China, vitiligo is quite common. Some epidemiological studies have been conducted and reported prevalence of vitiligo was $0.1 \%$ to $0.56 \%$. The most common clinical type was non segmental vitiligo. The pathogenesis of vitiligo is still not fully understood and there is a plethora of different treatments. In China, various treatments for vitiligo are available including topical treatment, UV irradiation and surgical treatment. Chinese Working Group for Vitiligo has made a guideline for treatment of vitiligo which helps Chinese dermatologists to use proper treatment and achieve good effects.
\end{abstract}

Keywords: Vitiligo; Epidemiology; Treatment; China

\section{Introduction}

Vitiligo is an acquired skin disorder characterized by patchy depigmentation of the skin [1]. Vitiligo affects approximately $0.5 \%$ to $2 \%$ of the population worldwide, and the prevalence appears to be equal between men and women [2,3]. The pathogenesis of vitiligo is still not fully understood and mounting evidences have suggested that it might be related to autoimmunity and oxidative stress [4]. Although neither life-threatening nor symptomatic, the effect of vitiligo can be cosmetically and psychologically devastating, resulting in low selfesteem, poor body image and other negative effects [5-7]. In this review, we focus on the epidemiology and treatment of vitiligo in China.

\section{Epidemiology}

\section{Prevalence of vitiligo}

Although vitiligo occurs worldwide, it is known that its prevalence varies between races and regions. Recent studies have revealed the prevalence from $0.06-2.28 \%$ [8-28]. Howitz et al. [8] reported that the prevalence of vitiligo in Denmark was $0.38 \%$. Mehta et al. [9] reported that the prevalence was $0.49 \%$ in rural areas of Indian and $1.78 \%$ in urban areas. Abdel-Hafez et al. [10] performed a survey in Upper Egypt and found the prevalence of vitiligo to be $1.2 \%$. In USA, the prevalence of vitiligo was $0.74 \%$ [11]. Other studies have shown a prevalence of $0.17 \%$ in Italy [12], $0.5-1 \%$ in the French West Indies [13], and $0.28 \%$ in France [14]. In China, several studies have been performed and the prevalence of vitiligo ranged from 0.10 to $0.3 \%$ [15-19]. Lu et al. [15] conducted a survey in Shaanxi province, northwest China and found that the prevalence of vitiligo was $0.10 \%$. In 2008 , a population-based and dermatologist-confirmed survey was conducted in 6 cities in China and the prevalence of vitiligo was $0.56 \%$ [16].

\section{Gender distribution}

Discrepancy on prevalence of psoriasis in men and women has been reported. Most studies showed similar prevalence between men and women [3]. Lu et al. [15] reported vitiligo distributed equally in men and women. However, Wang et al. [16] found a higher prevalence in male than in female. The male to female ratio was $1.6: 1$, which is similar to that reported by McBurney [29]. In a hospital-based study, Boisseau-Garsaud et al. [13] found more female patients than male patients, suggesting that women are more concerned about vitiligo.

\section{Age of onset}

Although vitiligo can occur at any age, it is more common in young and middle-aged people. A study reported that the mean age of onset was 18.9 years [30], while another study found that the mean age of onset was 23.7 years old [31]. Furthermore, it was also reported that vitiligo occurred at 28.4 years old in men and 17.3 years old in women, suggesting that vitiligo occurs earlier in women than in men [18].

\section{Type of vitiligo}

Recently, new classification and nomenclatures have been proposed based on clinical features: segmental vitiligo (SV) and non-segmental vitiligo (NSV). The latter including the variants focal, generalized, acrofacial and universal vitiligo. In China, the NSV is the most common form. Wang et al. [16] reported that of 122 patients, 44 (36.1\%) had focal vitiligo and 43 (35.3\%) had generalized vitiligo. Universal vitiligo was found in 22 patients (18.0\%) and acrofacial vitiligo was found in 10 patients $(8.2 \%)$. Only 3 patients $(2.5 \%)$ was segmental vitiligo. The types of vitiligo were similar between men and women. Similar results were obtained in other studies [18,31].

\section{Genetics}

The involvement of genetic factors in the susceptibility to vitiligo became evident in familial studies, which demonstrated that vitiligo segregates with a complex standard of multifactorial and polygenic inheritance [32-38]. A study reported that $20 \%$ of the patients had positive family history in first-degree relatives [33]. The relative risk of vitiligo in Denmark and India populations was 7 for parents, 12 for siblings, and 36 for off-spring. The relative risk of vitiligo for firstdegree relatives in increased 7 to 10 fold [36-38]. In China, 5\%-20\% patients with vitiligo had positive family history $[17,18,31]$. Sun et al. [18] reported that 128 patients out of $815(15.7 \%)$ had positive family history, and the heritability degrees of vitiligo in the first- and seconddegree relatives were $59.6 \%$ and $55.2 \%$, respectively. In another study, the positive family history was $9.8 \%[16]$.

\section{Management}

The Chinese Working Group for Vitiligo has made a guideline for management of vitiligo in 2009 [39]. The aims of treatment include controlling of the disease progress, promoting the repigmentation,

*Corresponding author: Jianzhong Zhang, Department of Dermatology, Peking University People's Hospital, No. 11 Xizhimen South Street, Xicheng District Beijing, 100044, PR China, Tel: 86-10-8832-5965; E-mail:rmzjz@126.com

Received: November 01, 2014; Accepted: November 13, 2014; Published: November 15, 2014

Citation: Ding X, Du J, Zhang J (2014) The Epidemiology and Treatment of Vitiligo: A Chinese Perspective. Pigmentary Disorders 1:148. doi: 10.4172/23760427.1000148

Copyright: (c) 2014 Ding X, et al. The terms of the Creative Commons Attribution License, which permits unrestricted use, distribution, and reproduction in any medium, provided the original author and source are credited. 
reducing treatment side effects and improving the quality of life. As the treatment often extends over a long period of time, the treatment strategy should be fully discussed with the patient to obtain a good compliance.

Topical steroids, topical calcineurin inhibitors and UV therapy were widely used in China. Psoralen plus ultravoilet A (PUVA) therapy and broadband (BB)-UVB were less used because of the high risk of side effects. The combination treatments for vitiligo are recommended. Camouflaging was used in some patients with severe and stable vitiligo. Topical bleaching agents are rarely applied in China.

\section{Topical treatments}

Topical corticosteroids: Topical corticosteroids is the most prevalent treatment for vitiligo [39-44]. It is the first-line therapy for progressive vitiligo with less than $10 \%$ body surface area (BSA) involvements [39]. The best results were found on sun-exposed areas (face and neck) [45,46], in dark skin [47], and in recentdeveloped lesions [48]. Lesions on hands and feet usually had a poor response. A study assessed the effectiveness and safety of nonsurgical repigmentation therapies in localized and generalized vitiligo by means of a meta-analysis. The results revealed that Class 3 corticosteroids therapy was the most effective and safest therapy for localized vitiligo [45]. It may require a year or longer to note significant improvement [49]. Less than $50 \%$ of patients achieve greater than $75 \%$ repigmentation after 10 months of treatment [49]. Potent and very potent TCS were widely used for the treatment of vitiligo in China and skin side-effect reports were not common [39].

Topical calcineurin inhibitors: The safety and efficacy of topical calcineurin inhibitors in patients with vitiligo has been evaluated in recent years [50-61]. Two left-right comparative studies showed that tacrolimus had similar effects to clobetasol propionate $0.05 \%$ in the treatment of pediatric patients $[51,52]$. Pimecrolimus was also effective [53]. In an open study comparing topical pimecrolimus and tacrolimus, both drugs showed similar effects [54]. In another open study, Lotti et al. [55] reported a higher response rate in tacrolimus group (61\%) than in pimecrolimus group (54.6\%). In a Chinese study, $83.9 \%$ patients treated with tacrolimus ointment were effective and $45.1 \%$ had complete or excellent response. It also showed that tacrolimus ointment was effective in both active and stable stages. Lesions on face and anogenital area had better response than other areas [56]. After the clinical trial, $61.7 \%$ of patients continued to use tacrolimus ointment, indicating that they were satisfied with the effects of tacrolimus and had a strong desire to continue the treatment [57]. Some studies showed that tacrolimus combined with narrowband UVB or 308-nm excimer laser therapy was superior to phototherapy alone or tacrolimus monotherapy $[60,61]$. The common side-effects of tacrolimus ointment were skin irritation (burning sensation, pruritus and erythema).

Vitamin D analogues: Topical Vitamin D analogues such as calcipotriol, tacalcitol have been used as monotherapy or in combination with topical corticosteroids or phototherapy for the treatment of vitiligo [62-65]. However, the effects remained controversial. A right-left comparative study was performed to compare the efficacy and safety of topical calcipotriol $(0.005 \%)$ and NB-UVB combination thrapy with NB-UVB alone in generalized vitiligo. The results showed that the effects of combination therapy were similar to NB-UVB monotherapy [66]. A similar results had been obtained in a study comparing calcipotriol and $308 \mathrm{~nm}$ excimer laser combination therapy and $308 \mathrm{~nm}$ excimer laser alone [67]. An open, uncontrolled trial was carried out to observe the effect of calcipotriol and betamethasone dipropionate combination therapy in the treatment of vitiligo. Patients were treated with topical calcipotriol $0.005 \% /$ betamethasone dipropionate $0.05 \%$ ointment twice a day. At the end of 12 weeks, 9.7\% showed excellent response, $19.4 \%$ showed moderate response [64].

\section{Phototherapy}

PUVA: Psoralen plus UVA therapy has been used to treat vitiligo for half a century. Oral or topical psoralen (solutions, creams or bath) was followed by UVA irradiation and it was effective for vitiligo [68]. Khellin plus UVA radiation (KUVA) was also reported to be effective for vitiligo [69]. Valkova [70] conducted a study to evaluate the efficacy of topical KUVA and systemic PUVA for vitiligo. It showed that topical KUVA required longer duration of treatment and higher UVA doses. No side effects were observed. In china, PUVA was less used for the treatment of vitiligo especially oral PUVA because of the high risk of side effects.

Narrowband UVB: Narrowband UVB represents a symbol of a specific UVB wave, $311 \pm 2 \mathrm{~nm}$. NB-UVB therapy was used for the treatment of vitiligo in 1990s [71-73]. Randomized, controlled trials have found that NB-UVB phototherapy is effective and safe for vitiligo [74,75]. Kishan [76] evaluted the efficacy and safety of NB-UVB in 150 vitiligo patients. The results showed 26(17.3\%) patients achieved $>75 \%$ repigmentation. $73(48.7 \%)$ patients achieved $25-75 \%$ repigmentation. Adverse effects were minimal. Another randomized controlled study [77] compared the efficacy of NB-UVB with oral PUVA in the treatment of vitiligo. 56 patients were randomized in a 1:1 ratio to oral PUVA or NBUVB phototherapy. The median repigmentation achieved at the end of the six-month therapy course was $45 \%$ in the NB-UVB group and $40 \%$ in oral PUVA group. Less adverse effects was found in NB-UVB group (7.4\%) than in PUVA group (57.2\%). There was no significant difference in repigmentation. However, NB-UVB showed better tolerance and less side effects. In China, NB-UVB phototherapy is widely used because of its good efficacy safety profile.

$308 \mathrm{~nm}$ excimer laser/light: $308 \mathrm{~nm}$ excimer laser/light therapy can radiate $308 \mathrm{~nm}$ UVB to targeted areas of vitiligo. It is useful for spotted and patched vitiligo lesions. $15-50 \%$ of $308 \mathrm{~nm}$ excimer lasertreated lesions showed excellent results ( $>75 \%$ repigmentation) [42]. A few studies have been conducted in China to evaluate the efficacy of $308 \mathrm{~nm}$ excimer laser/light in vitiligo treatment [78,79]. In one study, 36 patients with 44 vitiligo patches were treated using a $308 \mathrm{~nm}$ excimer laser. After 30 treatments $27 / 44$ patches (61.4\%) achieved more than $75 \%$ repigmentation [78]. Another study was performed [80] to compare the efficacy of $308 \mathrm{~nm}$ excimer laser with $308 \mathrm{~nm}$ excimer lamp in the treatment of vitiligo. Fourteen patients with a total of 48 lesions were treated. The results showed that $308 \mathrm{~nm}$ excimer laser with $308 \mathrm{~nm}$ excimer lamp had the similar effects [80].

\section{Epidermal Grafting and surgical treatments}

Skin grafts were first used for the treatment of vitiligo in the 1960s and became prevalent in 1980s. Five surgical methods are predominant, including: (i) split-thickness skin grafting; (ii) epidermal grafting; (iii) mini-grafting; (iv) autologous non-cultured melanocyte-keratinocyte cell transplantation/injection; and (v) autologous cultured melanocyte transplantation/injection. The UK guideline for management of vitiligo recommended that surgical treatment should be used only for cosmetically sensitive sites where there have been no new lesions, no Koebner's phenomenon and no extension of the lesion in the previous 12 months [40]. In China, autologous epidermal grafting was the most common surgical treatment for vitiligo [81]. Jin et al. [82] reported that $86.81 \%$ patients receiving autologous epidermal transplantation had satisfied repigmentation. Hyperpigmentation was 
found in $24.52 \%$ patients and hypopigmentation in $21.29 \%$ patients. $\mathrm{Xu}$ et al. [83] reported that successful repigmentation was obtained in 23 of the 24 patients who received autologous non-cultured epidermal cell suspension transplatation. Hong et al. [84] performed autologous cultured pure melanocytes transplantation in pediatric and adult patients. The results showed that $83.3 \%$ pediatric patients and $84.0 \%$ adult patients obtained satisfactory results (repigmentation of $50 \%$ or more).

\section{Systemic treatment}

The systemic therapies for vitiligo include oral corticosteroids, immunosuppresive agents, oral antioxidants and others. Corticosteroids can be used for short period of time in patients with progressive vitiligo. Kim et al. [85] studied the efficacy of low-dose oral corticosteroids for vitiligo. The initial dose was oral prednisolone $0.3 \mathrm{mg} / \mathrm{kg}$ for 2 months, then the dose reduced for half every month. After 5 month treatment, $70.4 \%$ patients showed repigmentation. Immunosuppressants have been evaluated in a limited number of studies and rarely used by Chinese dermatologists. Recently, topical and systemic antioxidants were tried in the treatment of vitiligo. Pseudocatalase, vitamin E, vitamin C, ubiquinone, lipoic acid, polypodium leucotomos, catalase/superoxide dismutase combination, and Ginkgo biloba have been used alone or, more frequently, in combination with phototherapy for vitiligo. The clinical effects need to be confirmed [86-88].

\section{Conclusion}

Vitiligo is a common acquired depigmenting skin disorder and has a negative impact on patients' quality of life. The prevalence of vitiligo in China varied from $0.1 \%$ to $0.56 \%$. Topical steroids, topical calcineurin inhibitors, UVB therapy and autologous epidermal graft are the most used treatment for vitiligo.

\section{References}

1. Yaghoobi R, Omidian M, Bagherani N (2011) Vitiligo: a review of the published work. J Dermatol 38: 419-431.

2. Kyriakis KP, Palamaras I, Tsele E, Michailides C, Terzoudi S (2009) Case detection rates of vitiligo by gender and age. Int J Dermatol 48: 328-329.

3. Allam M, Riad H (2013) Concise review of recent studies in vitiligo. Qatar Med J 2013: 1-19.

4. Alkhateeb A, Fain PR, Thody A, Bennett DC, Spritz RA (2003) Epidemiology of vitiligo and associated autoimmune diseases in Caucasian probands and their families. Pigment Cell Res 16: 208-214.

5. Alikhan A, Felsten LM, Daly M, Petronic-Rosic V (2011) Vitiligo: a comprehensive overview Part I. Introduction, epidemiology, quality of life, diagnosis, differential diagnosis, associations, histopathology, etiology, and work-up. J Am Acad Dermatol 65: 473-491.

6. Mattoo SK, Handa S, Kaur I, Gupta N, Malhotra R (2002) Psychiatric morbidity in vitiligo: prevalence and correlates in India. J Eur Acad Dermatol Venereol 16: $573-578$

7. Ongenae K, Van Geel N, De Schepper S, Naeyaert JM (2005) Effect of vitiligo on self-reported health-related quality of life. Br J Dermatol 152: 1165-1172.

8. Howitz J, Brodthagen H, Schwartz M, Thomsen K (1977) Prevalence of vitiligo. Epidemiological survey on the Isle of Bornholm, Denmark. Arch Dermatol 113: 47-52.

9. Mehta NR, Shah KC, Theodore C, Vyas VP, Patel AB (1973) Epidemiologica study of vitiligo in Surat area, South Gujarat. Indian J Med Res 61: 145-154.

10. Abdel-Hafez K, Abdel-Aty MA, Hofny ER (2003) Prevalence of skin diseases in rural areas of Assiut Governorate, Upper Egypt. Int J Dermatol 42: 887-892.

11. Rose NR, Mackay IR (1998) The Autoimmune Diseases (3rdedtn) Academic Press, San Diego, CA, USA 141-149.

12. Ingordo V, Gentile C, lannazzone SS, Cusano F, Naldi L (2007) The 'EpiEnlist' project: a dermo-epidemiologic study on a representative sample of young
Italian males. Prevalence of selected pigmentary lesions. J Eur Acad Dermatol Venereol 21: 1091-1096.

13. Boisseau-Garsaud AM, Garsaud $P$, Calès-Quist $D$, Hélénon $R$, Quénéhervé C, et al. (2000) Epidemiology of vitiligo in the French West Indies (Isle of Martinique). Int J Dermatol 39: 18-20.

14. Wolkenstein P, Grob JJ, Bastuji-Garin S, Ruszczynski S, Roujeau JC, et al. (2003) French people and skin diseases: results of a survey using a representative sample. Arch Dermatol 139: 1614-1619.

15. Lu T, Gao T, Wang A, Jin Y, Li Q, et al. (2007) Vitiligo prevalence study in Shaanxi Province, China. Int J Dermatol 46: 47-51.

16. Wang X, Du J, Wang T, Zhou C, Shen Y, et al. (2013) Prevalence and clinical profile of vitiligo in China: a community-based study in six cities. Acta Derm Venereol 93: 62-65.

17. Xu YY, Ye DQ, Tong ZC (2002) An epidemiological survey on four skin diseases in Anhui. Chin J Dermatol 35: 406-407.

18. Sun TQ, Niu LJ, Liu T (1999) An epidemiological survey of vitiligo in Taian Shandong province. J Dermatol Venereol 21: 25-26.

19. Li Y, Xu A (2013) Segmental vitiligo in children: a clinical epidemiologic study in China. J Eur Acad Dermatol Venereol 27: 1056-1057.

20. Chen GY, Cheng YW, Wang CY, Hsu TJ, Hsu MM, et al. (2008) Prevalence of skin diseases among schoolchildren in Magong, Penghu, Taiwan: a communitybased clinical survey. J Formos Med Assoc 107: 21-29.

21. Dogra S, Kumar B (2003) Epidemiology of skin diseases in school children: a study from northern India. Pediatr Dermatol 20: 470-473.

22. Birlea SA, Fain PR, Spritz RA (2008) A Romanian population isolate with high frequency of vitiligo and associated autoimmune diseases. Arch Dermatol 144 310-316.

23. Figueroa JI, Fuller LC, Abraha A, Hay RJ (1998) Dermatology in southwestern Ethiopia: rationale for a community approach. Int J Dermatol 37: 752-758.

24. Vanderhooft SL, Francis JS, Pagon RA, Smith LT, Sybert VP (1996) Prevalence of hypopigmented macules in a healthy population. J Pediatr 129: 355-361.

25. Gibbs S (1996) Skin disease and socioeconomic conditions in rural Africa: Tanzania. Int J Dermatol 35: 633-639.

26. Kubeyinje EP, Belagavi CS (1997) Skin and treponemal diseases among Asian domestic house-helpers in northern Saudi Arabia. Int J Dermatol 36: 650-652.

27. Naldi L, Colombo P, Placchesi EB, Piccitto R, Chatenoud L, et al. (2004) Study design and preliminary results from the pilot phase of the PraKtis study: selfreported diagnoses of selected skin diseases in a representative sample of the Italian population. Dermatology 208: 38-42.

28. Walker SL, Shah M, Hubbard VG, Pradhan HM, Ghimire M (2008) Skin disease is common in rural Nepal: results of a point prevalence study. $\mathrm{Br} \mathrm{J}$ Dermatol 158: 334-338.

29. McBurney El (1979) Vitiligo. Clinical picture and pathogenesis. Arch Intern Med 139: 1295-1297.

30. Liu JB, Li M, Yang S, Gui JP, Wang HY, et al. (2005) Clinical profiles of vitiligo in China: an analysis of 3742 patients. Clin Exp Dermatol 30: 327-331.

31. Mchepange UO, Gao XH, Liu YY, Liu YB, Ma L, et al. (2010) Vitiligo in NorthEastern China: An association between mucosal and acrofacial lesions. Acta Derm Venereol 90: 136-140.

32. Zhang XJ, Liu JB, Gui JP, Li M, Xiong QG, et al. (2004) Characteristics of genetic epidemiology and genetic models for vitiligo. J Am Acad Dermatol 51 383-390.

33. Majumder PP, Nordlund JJ, Nath SK (1993) Pattern of familial aggregation of vitiligo. Arch Dermatol 129: 994-998.

34. Tarlé RG, Nascimento LM, Mira MT, Castro CC (2014) Vitiligo--part 1. An Bras Dermatol 89: 461-470.

35. Zhang XJ, Chen JJ, Liu JB (2005) The genetic concept of vitiligo. J Dermato Sci 39: 137-146.

36. Czajkowski R, MÄ ${ }^{T M}$ ci $\AA$,,ska-Jundziß̊,Å, K (2014) Current aspects of vitiligo genetics. Postepy Dermatol Alergol 31: 247-255.

37. Bhatia PS, Mohan L, Pandey ON, Singh KK, Arora SK, et al. (1992) Genetic nature of vitiligo. J Dermatol Sci 4: 180-184 
38. Nath SK, Majumder PP, Nordlund JJ (1994) Genetic epidemiology of vitiligo: multilocus recessivity cross-validated. Am J Hum Genet 55: 981-990.

39. Working Group for Vitiligo of China Society of Dermatology (2009) Guidelines for management of vitiligo 2009. Chin J Dermatol 42: 591-592.

40. Gawkrodger DJ, Ormerod AD, Shaw L, Mauri-Sole I, Whitton ME, et al. (2008) Guideline for the diagnosis and management of vitiligo. $\mathrm{Br} \mathrm{J}$ Dermatol 159 : 1051-1076.

41. Gawkrodger DJ, Ormerod AD, Shaw L, Mauri-Sole I, Whitton ME, et al. (2010) Vitiligo: concise evidence based guidelines on diagnosis and management. Postgrad Med J 86: 466-471.

42. Oiso N, Suzuki T, Wataya-Kaneda M, Tanemura A, Tanioka M, et al. (2013) Guidelines for the diagnosis and treatment of vitiligo in Japan. J Dermatol 40 344-354

43. Taieb A, Alomar A, Böhm M, Dell'anna ML, De Pase A, et al. (2013) Guidelines for the management of vitiligo: the European Dermatology Forum consensus. Br J Dermatol 168: 5-19.

44. Zhang Y, Mooneyan-Ramchurn JS, Zuo N, Feng Y, Xiao S (2014) Vitiligo nonsurgical treatment: a review of latest treatment researches. Dermatol Ther 27: $298-303$

45. Njoo MD, Spuls PI, Bos JD, Westerhof W, Bossuyt PM (1998) Nonsurgical repigmentation therapies in vitiligo. Meta-analysis of the literature. Arch Dermatol 134: 1532-1540.

46. Westerhof W, Nieuweboer-Krobotova L, Mulder PG, Glazenburg EJ (1999) Left-right comparison study of the combination of fluticasone propionate and UV-A vs. either fluticasone propionate or UV-A alone for the long-term treatment of vitiligo. Arch Dermatol 135: 1061-1066.

47. Kumari J (1984) Vitiligo treated with topical clobetasol propionate. Arch Dermatol 120: 631-635.

48. Schaffer JV, Bolognia JL (2003) The treatment of hypopigmentation in children. Clin Dermatol 21: 296-310.

49. Sanclemente G, Garcia JJ, Zuleta JJ, Diehl C, Correa C, et al. (2008) A doubleblind, randomized trial of $0.05 \%$ betamethasone vs. topical catalase/dismutase superoxide in vitiligo. J Eur Acad Dermatol Venereol 22: 1359-1364.

50. Wong R, Lin AN (2013) Efficacy of topical calcineurin inhibitors in vitiligo. Int J Dermatol 52: 491-496.

51. Ho N, Pope E, Weinstein M, Greenberg S, Webster C, et al. (2011) A doubleblind, randomized, placebo-controlled trial of topical tacrolimus $0.1 \%$ vs. clobetasol propionate $0.05 \%$ in childhood vitiligo. $\mathrm{Br} J$ Dermatol 165: 626-632.

52. Lepe V, Moncada B, Castanedo-Cazares JP, Torres-Alvarez MB, Ortiz CA, et al. (2003) A double-blind randomized trial of $0.1 \%$ tacrolimus vs $0.05 \%$ clobetasol for the treatment of childhood vitiligo. Arch Dermatol 139: 581-585.

53. Coskun B, Saral Y, Turgut D (2005) Topical $0.05 \%$ clobetasol propionate versus $1 \%$ pimecrolimus ointment in vitiligo. Eur J Dermatol 15: 88-91.

54. Stinco G, Piccirillo F, Forcione M, Valent F, Patrone P (2009) An open randomized study to compare narrow band UVB, topical pimecrolimus and topical tacrolimus in the treatment of vitiligo. Eur J Dermatol 19: 588-593.

55. Lotti T, Buggiani G, Troiano M, Assad GB, Delescluse J, et al. (2008) Targeted and combination treatments for vitiligo. Comparative evaluation of different current modalities in 458 subjects. Dermatol Ther 21 Suppl 1: S20-26.

56. Juan D, Qianxi X, Zhou C, Jianzhong Z (2011) Clinical efficacy and safety of tacrolimus ointment in patients with vitiligo. J Dermatol 38: 1092-1094.

57. Du J, Wang XY, Ding XL, Xu QX, Chen Z, et al. (2013) Long-term efficacy and safety of tacrolimus ointment in the treatment of vitiligo. J Dermatol 40 : 935-936

58. Lo YH, Cheng GS, Huang CC, Chang WY, Wu CS (2010) Efficacy and safety of topical tacrolimus for the treatment of face and neck vitiligo. J Dermatol 37: 125-129.

59. Bhuvana K, Sarala N, Singh G, Kumar TN (2011) Effect of $0.1 \%$ tacrolimus ointment in localized vitiligo: an open uncontrolled trial. Indian J Dermatol 56: $445-446$.

60. Matin M, Latifi S, Zoufan N, Koushki D, Mirjafari Daryasari SA, et al. (2014) The effectiveness of excimer laser on vitiligo treatment in comparison with a combination therapy of Excimer laser and tacrolimus in an Iranian population. J Cosmet Laser Ther 16: 241-245.
61. Satyanarayan HS, Kanwar AJ, Parsad D, Vinat K (2013) Efficacy and tolerability of combined treatment with NB-UVB and topical tacrolimus versus NB-UVB alone in patients with vitiligo vulgaris: a randomized intra-individual open comparative trial. Indian J Dermatol Venereol Leprol 79: 525-527.

62. Gargoom AM, Duweb GA, Elzorghany AH, Benghazil M, Bugrein OO (2004) Calcipotriol in the treatment of childhood vitiligo. Int J Clin Pharmacol Res 24 $11-14$

63. Newman MD, Silverberg NB (2011) Once-daily application of calcipotriene $0.005 \%$-betamethasone dipropionate $0.064 \%$ ointment for repigmentation of facial vitiligo. Cutis 88: 256-259.

64. Xing C, Xu A (2012) The effect of combined calcipotriol and betamethasone dipropionate ointment in the treatment of vitiligo: an open, uncontrolled trial. $J$ Drugs Dermatol 11: e52-54.

65. Goktas EO, Aydin F, Senturk N, Canturk MT, Turanli AY (2006) Combination of narrow band UVB and topical calcipotriol for the treatment of vitiligo. J Eur Acad Dermatol Venereol 20: 553-557.

66. Khullar G, Kanwar AJ, Singh S, Parsad D (2014) Comparison of efficacy and safety profile of topical calcipotriol ointment in combination with NB-UVB vs. NB-UVB alone in the treatment of vitiligo: a 24-week prospective right-left comparative clinical trial. J Eur Acad Dermatol Venereol.

67. Goldinger SM, Dummer R, Schmid P, Burg G, Seifert B, et al. (2007) Combination of 308-nm xenon chloride excimer laser and topical calcipotriol in vitiligo. J Eur Acad Dermatol Venereol 21: 504-508.

68. Pathak MA (1984) Mechanisms of psoralen photosensitization reactions. Nat Cancer Inst Monogr 66: 41-46.

69. Hofer A, Kerl H, Wolf $P$ (2001) Long-term results in the treatment of vitiligo with oral khellin plus UVA. Eur J Dermatol 11: 225-229.

70. Valkova S, Trashlieva M, Christova P (2004) Treatment of vitiligo with loca khellin and UVA: comparison with systemic PUVA. Clin Exp Dermatol 29: 180184.

71. Westerhof W, Nieuweboer-Krobotova L (1997) Treatment of vitiligo with UV-B radiation vs topical psoralen plus UV-A. Arch Dermatol 133: 1525-1528.

72. Njoo MD, Bos JD, Westerhof W (2000) Treatment of generalized vitiligo in children with narrow-band (TL-01) UVB radiation therapy. J Am Acad Dermato 42: $245-253$

73. Scherschun L, Kim JJ, Lim HW (2001) Narrow-band ultraviolet B is a useful and well-tolerated treatment for vitiligo. J Am Acad Dermatol 44: 999-1003.

74. Hamzavi I, Jain H, McLean D, Shapiro J, Zeng H, et al. (2004) Parametric modeling of narrowband UV-B phototherapy for vitiligo using a nove quantitative tool: the Vitiligo Area Scoring Index. Arch Dermatol 140: 677-683.

75. Yones SS, Palmer RA, Garibaldinos TM, Hawk JL (2007) Randomized double-blind trial of treatment of vitiligo: efficacy of psoralen-UV-A therapy vs Narrowband-UV-B therapy. Arch Dermatol 143: 578-584

76. Kishan Kumar YH, Rao GR, Gopal KV, Shanti G, Rao KV (2009) Evaluation of narrow-band UVB phototherapy in 150 patients with vitiligo. Indian J Dermatol Venereol Leprol 75: 162-166.

77. Sapam R, Agrawal S, Dhali TK (2012) Systemic PUVA vs. narrowband UVB in the treatment of vitiligo: a randomized controlled study. Int J Dermatol 51 1107-1115.

78. Zhang XY, He YL, Dong J, Xu JZ, Wang J (2010) Clinical efficacy of a 308 $\mathrm{nm}$ excimer laser in the treatment of vitiligo. Photodermatol Photoimmunol Photomed 26: 138-142.

79. Hui-Lan Y, Xiao-Yan H, Jian-Yong F, Zong-Rong L (2009) Combination of 308-nm excimer laser with topical pimecrolimus for the treatment of childhood vitiligo. Pediatr Dermatol 26: 354-356.

80. Shi Q, Li K, Fu J, Wang Y, Ma C, et al. (2013) Comparison of the 308-nm excimer laser with the 308-nm excimer lamp in the treatment of vitiligo-a randomized bilateral comparison study. Photodermatol Photoimmunol Photomed 29: 27-33.

81. Li J, Fu WW, Zheng ZZ, Zhang QQ, Xu Y, et al. (2011) Suction blister epidermal grafting using a modified suction method in the treatment of stable vitiligo: a retrospective study. Dermatol Surg 37: 999-1006.

82. Jin $Y, X u A$, Wang $P$, Song $X$, Liu X (2011) Long-term follow-up and correlated factors of vitiligo following autologous epidermal transplantation. Cutis 87: 137 141

83. Xu AE, Wei XD, Cheng DQ, Zhou HF, Qian GP (2005) Transplantation of 
Citation: Ding X, Du J, Zhang J (2014) The Epidemiology and Treatment of Vitiligo: A Chinese Perspective. Pigmentary Disorders 1:148. doi: 10.4172/2376-0427.1000148

autologous noncultured epidermal cell suspension in treatment of patients with stable vitiligo. Chin Med J (Engl) 118: 77-79.

84. Hong WS, Hu DN, Qian GP, McCormick SA, Xu AE (2011) Treatment of vitiligo in children and adolescents by autologous cultured pure melanocytes transplantation with comparison of efficacy to results in adults. J Eur Acad Dermatol Venereol 25: 538-543.

85. Kim SM, Lee HS, Hann SK (1999) The efficacy of low-dose oral corticosteroids in the treatment of vitiligo patients. Int J Dermatol 38: 546-550.

86. Colucci R, Dragoni F, Conti R, Pisaneschi L, Lazzeri L, et al. (2014) Evaluation of an oral supplement containing Phyllanthus emblica fruit extracts, vitamin E, and carotenoids in vitiligo treatment. Dermatol Ther

87. Elgoweini M, Nour EI Din N (2009) Response of vitiligo to narrowband ultraviolet B and oral antioxidants. J Clin Pharmacol 49: 852-855.

88. Dell'Anna ML, Mastrofrancesco A, Sala R, Venturini M, Ottaviani M, et al. (2007) Antioxidants and narrow band-UVB in the treatment of vitiligo: a doubleblind placebo controlled trial. Clin Exp Dermatol 32: 631-636. 